\title{
Duodenal ulcer and refined carbohydrate intake: a case-control study assessing dietary fibre and refined sugar intake
}

\author{
Bettina D Katschinski, R F A Logan, Margaret Edmond, M J S Langman
}

\begin{abstract}
An association between duodenal ulceration and a low fibre intake and a high refined carbohydrate diet has been reported. We therefore compared the current diet, smoking habits, social class, and possible other risk factors of 78 patients with duodenal ulcer and a community control group matched for age and sex. Logistic regression for matched sets was used to calculate the relative risks for successive quintiles of dietary fibre and sugar intake before and after adjustment for total calorie intake and for the possible confounding effect of other known risk factors. Relative risks did not differ materially or consistently for total dietary fibre or for the cereal moiety whether adjusted or not for calorie intake. By contrast, relative risks tended to be reduced with high vegetable fibre intake and with low refined sugar intake. After controlling for smoking and social class, both of which were associated with ulcer disease, and for relative weight (Quetelet's index), the relation between ulcer disease and low refined sugar intake persisted, while that with high vegetable fibre intake was reduced. The results of this study indicate that a lack of cereal or total fibre intake plays no part in duodenal ulcer development but that a low refined sugar intake may be a protective factor.
\end{abstract}

A major influence of dietary factors on the incidence of peptic ulcer is widely assumed, but there are few supporting data.' Geographical comparisons of peptic ulcer frequency have been used to emphasise, among other things, the high frequency of duodenal ulcer in south India and Assam compared to north India, and the raised frequency of ulcer in selected parts of Africa, such as south Nigeria compared with north Nigeria. ${ }^{23}$ These findings have been adduced in suggesting that a high fibre intake may be protective against ulcer. In addition, analysis of the pronounced secular changes in ulcer frequency in Europe and North America during this century led Cleave to suggest that the introduction of refined carbohydrate foods was responsible for the increase in ulcer disease as a consequence of the loss of buffering protein. ${ }^{45}$ Finally, it has been reported that fibre rich diets will reduce ulcer recurrence rates in patients with duodenal ulcer disease. ${ }^{67}$

The relation between the intake of refined foods and the risk of duodenal ulceration has not been examined in case-control or cohort studies, and we have therefore carried out a case-control comparison.

\section{Methods}

ASSESSMENT OF PATIENTS

All patients aged 20 to 60 years who had a duodenal ulcer identified by endoscopy in the two major hospitals in Nottingham between 1 April 1985 and 31 March 1986 were considered. Patients with episodic recurrence of symptoms in the last two years were excluded to reduce the effect of dietary change consequent upon chronic disease. Patients who had a medical disorder requiring dietary treatment such as diabetes, or serious psychiatric illness were also excluded. Patients in whom a duodenal ulcer had been diagnosed by barium meal were not considered. Table I summarises details of the patient series.

\section{ASSESSMENT OF CONTROL SUBJECTS}

Each patient was matched with two control subjects who lived in the same area of Nottingham as the patient. Matched control subjects were selected by visiting a general practitioner's surgery in that area and identifying from the surgery records the next two subjects of the same sex and age within 5 years who were listed alphabetically after the patient's surname. Those with a history of peptic ulceration, diabetes, or life threatening or terminal disease were not considered. In the United Kingdom $98 \%$ of the population are registered with general practitioners.

Control subjects were identified from the records of 12 general practices which were chosen to reflect the range of neighbourhoods and living conditions experienced by the patients.

METHOD OF INQUIRY

Patients and control subjects were sent identical

TABLE I Details of patients and control subjects responding to questionnaire

\begin{tabular}{|c|c|c|c|}
\hline & $\begin{array}{l}\text { Patients } \\
(\%)\end{array}$ & $\begin{array}{l}\text { Control } \\
\text { subjects } \\
(\%)\end{array}$ & $\begin{array}{l}\text { Relative risk } \\
\text { (95\% confidence } \\
\text { intervals) }\end{array}$ \\
\hline $\begin{array}{l}\text { No of patients replying } \\
\text { No of men } \\
\text { Mean age (years) } \\
\text { No aged > } 40 \text { years } \\
\text { Previous peptic ulceration } \\
\text { Previous operation on the }\end{array}$ & $\begin{array}{l}88 \\
70(80) \\
44 \\
63(72) \\
40(45)\end{array}$ & $\begin{array}{l}166 \\
130(78) \\
45 \\
123(74) \\
-\end{array}$ & \\
\hline $\begin{array}{l}\text { stomach } \\
\text { Smoking habits: }\end{array}$ & $19(22)$ & - & \\
\hline $\begin{array}{l}\text { Never smoked } \\
\text { Ex-smoker } \\
\text { Current smoker }\end{array}$ & $\begin{array}{l}12(14) \\
15(17) \\
61(69)\end{array}$ & $\begin{array}{l}46(28) \\
28(17) \\
92(55)\end{array}$ & $\begin{array}{l}1.0- \\
1.8(0.37 \text { to } 4.9) \\
2.2(1.03 \text { to } 4.7)\end{array}$ \\
\hline $\begin{array}{l}\text { Social class: } \\
\text { I and II } \\
\text { III } \\
\text { IV and V }\end{array}$ & $\begin{array}{l}15(17) \\
51(58) \\
22(25)\end{array}$ & $\begin{array}{l}48(29) \\
95(57) \\
23(14)\end{array}$ & $\begin{array}{l}1.0- \\
2.0(0.95 \text { to } 4.4) \\
3.7(1.4 \text { to } 9.5)\end{array}$ \\
\hline
\end{tabular} \\ Therapeutics, Medica Nottingham, Queen's Nottingham NG7 2UH B D Katschinski $M$ Edmond
$M$ J S Langman \\ Department of Community Medicine and Epidemiology, 30 October 1989}


TABLE II Intake of total fibre, cereal fibre, vegetable fibre, and refined sugar grouped into quintiles among control subjects $(n=166)$

\begin{tabular}{|c|c|c|c|c|c|}
\hline \multirow[b]{3}{*}{ Measurement } & \multicolumn{5}{|c|}{ Diet quintile } \\
\hline & \multicolumn{2}{|l|}{ Low } & \multirow[b]{2}{*}{3} & \multicolumn{2}{|l|}{ High } \\
\hline & 1 & 2 & & 4 & 5 \\
\hline $\begin{array}{l}\text { Total fibre (g/day) } \\
\text { Cereal fibre (g/day) } \\
\text { Vegetable fibre (g/day) } \\
\text { Refined sugar (g/day) }\end{array}$ & $\begin{array}{r}<12 \cdot 5 \\
<3 \cdot 3 \\
<7 \cdot 9 \\
<28 \cdot 3\end{array}$ & $\begin{array}{c}12 \cdot 5-<16 \cdot 3 \\
3 \cdot 3-<5 \cdot 6 \\
7 \cdot 9-<10 \cdot 8 \\
28 \cdot 3-<52 \cdot 3\end{array}$ & $\begin{array}{c}16 \cdot 3-<20 \cdot 8 \\
5 \cdot 6-<8 \cdot 1 \\
10 \cdot 8-<12 \cdot 6 \\
52 \cdot 3-<76 \cdot 7\end{array}$ & $\begin{array}{c}20 \cdot 8-<25 \cdot 4 \\
8 \cdot 1-<10 \cdot 8 \\
12 \cdot 6-<15 \cdot 1 \\
76 \cdot 7-<123 \cdot 5\end{array}$ & $\begin{array}{r}>25 \cdot 4 \\
>10 \cdot 8 \\
>15 \cdot 1 \\
>123 \cdot 5\end{array}$ \\
\hline
\end{tabular}

questionnaires by post. Demographic characteristics including occupation and marital state were included on the first page and dietary intake, assessed by means of a quantitative food frequency schedule that allowed estimation of the intake of specific nutrients, was considered in the main, middle section. We inquired about the frequency of intake of individual foods, particularly those containing dietary fibre derived from cereals or vegetables or refined sugar. We asked about the usual frequency of intake: daily, weekly, or monthly during the past year, and, by specifying portions in household measures we derived additional quantitative data. Finally, we inquired about possible dietary changes caused by indigestion and about possible confounding factors, especially smoking and drug intake.

If there was no response to the first questionnaire, second and, if necessary, third copies were sent six to eight weeks later.

\section{DATA ANALYSIS}

The individual nutrient intakes were estimated from food consumption using computerised food composition tables after allowing for differences in portion size. ${ }^{8-10}$ Levels of nutrient intakes were categorised by grouping the controls according to quintiles of individuals with ascending intakes of foods (Table II), and relative risks were estimated by comparing the proportions of patients and controls at each level of intake. The relative risk (RR) in the lowest quintile of nutrient intake was arbitrarily specified as 1.0 .

TABLE III Relative risks $(R R)^{\star}$ (and $95 \%$ confidence intervals) by quintiles of calorie adjusted and unadjusted intake of total fibre, subgroups of fibre, and refined sugar

\begin{tabular}{|c|c|c|c|c|c|}
\hline \multirow[b]{3}{*}{ Nutrient } & \multicolumn{5}{|c|}{ Quintile } \\
\hline & \multicolumn{2}{|c|}{ Lowest } & \multirow[b]{2}{*}{3} & \multicolumn{2}{|l|}{ Highest } \\
\hline & 1 & 2 & & 4 & 5 \\
\hline \multicolumn{6}{|l|}{ Total fibre: } \\
\hline Patients & 19 & 13 & 15 & 13 & 18 \\
\hline Control subjects & 31 & 30 & 30 & 30 & 30 \\
\hline Unadjusted $\mathbf{R R}$ & 1.0 & 0.97 & $1 \cdot 2$ & 0.70 & $1 \cdot 3$ \\
\hline Calorie adjusted & 1.0 & $\begin{array}{l}1.0 \\
(0.37 \text { to } 2.7)\end{array}$ & $\begin{array}{l}0.86 \\
(0.32 \text { to } 2.3)\end{array}$ & $\begin{array}{l}0.94 \\
(0.35 \text { to } 2.5)\end{array}$ & $\begin{array}{l}0.91 \\
(0.34 \text { to } 2.4)\end{array}$ \\
\hline \multicolumn{6}{|l|}{ Cereal fibre: } \\
\hline Patients & 21 & 13 & 12 & 11 & 21 \\
\hline Control subjects & 31 & & 30 & 30 & 30 \\
\hline Unadjusted RR & 1.0 & 0.52 & 0.58 & 0.44 & 1.0 \\
\hline Calorie adjusted & 1.0 & 1.6 & $\begin{array}{l}1.0 \\
0.26,0.7)\end{array}$ & 0.69 & $2 \cdot 0$ \\
\hline \multicolumn{6}{|l|}{ Vegetable fibre: } \\
\hline Patients & 25 & 11 & 13 & 14 & 15 \\
\hline Control subjects & & & 29 & 30 & 30 \\
\hline Unadjusted RR & 1.0 & 0.45 & 0.49 & 0.69 & 0.61 \\
\hline Calorie adjusted & 1.0 & 0.48 & 0.50 & 0.72 & 0.60 \\
\hline \multicolumn{5}{|l|}{ Refined sugar: } & $(0 \cdot 23$ to $1 \cdot 6)$ \\
\hline $\begin{array}{l}\text { Kenned sugar: } \\
\text { Patients }\end{array}$ & & 23 & 17 & 18 & 14 \\
\hline Control subjects & 31 & 30 & 30 & 30 & 30 \\
\hline Unadjusted RR & 1.0 & $4 \cdot 2$ & $2 \cdot 8$ & $3 \cdot 2$ & $2 \cdot 6$ \\
\hline Calorie adjusted & $1 \cdot 0$ & $4 \cdot 5$ & $3 \cdot 0$ & $4 \cdot 1$ & 3.7 \\
\hline & & $(1 \cdot 3$ to $15 \cdot 2)$ & $(0 \cdot 81$ to $11 \cdot 1)$ & $(1 \cdot 1$ to $15 \cdot 3)$ & $(1.0$ to 13.0$)$ \\
\hline
\end{tabular}

${ }^{\star}$ Logistic regression estimates.
Conditional logistic regression for matched sets was used to calculate relative risks (RR) with $95 \%$ confidence intervals adjusted for the effect of confounding variables. "Variables considered as potential confounders were total energy intake (five categories), social class (three categories), smoking (three categories), and Quetelet's index (weight/height ${ }^{2}$ ) as a measure of relative obesity (three categories).

Socioeconomic status as assessed by social class was based on the Registrar General's classification with subjects being classified on the basis of current occupation. ${ }^{12}$

\section{Results}

Sixty four of the 104 patients initially approached had new diagnoses of duodenal ulceration and 40 had recurrent ulceration but had been symptom free for at least the previous two years. In five cases the questionnaires were returned as the patient no longer resided at that address. Of the remaining 99 no replies were received from 11 , giving a response rate of $89 \%$. Likewise, 13 of 208 controls had moved away and 29 did not reply, giving a response rate of $85 \%$. For 10 of the patients and 15 of the controls completion of the dietary section of the questionnaire was inadequate for analysis.

Table I shows that the patients and control subjects who responded were well matched for age, but that there were more smokers and more patients in social classes IV and V than control subjects.

Table III shows the relative risks of duodenal ulcer disease according to quintile of fibre and sugar intake both unadjusted and adjusted for total energy intake. Relative risks according to quintile of total fibre intake were close to unity, and those for cereal fibre varied irregularly. Relative risks of ulcer were, however, approximately halved in those with higher vegetable fibre intakes, and were increased between three and fivefold in those with higher refined sugar intakes. In both these cases patterns were unaffected by adjusting for calorie intake, but in neither was there evidence of any gradient with increasing dietary intake.

To assess possible confounding factors the effects of smoking, social class, relative weight as assessed by Quetelet's index, and energy intake were examined. As shown in Table $I$, both smoking and low social class were associated with duodenal ulceration. A slightly increased risk was also evident for the highest compared to the lowest of three categories of Quetelet's index (RR $1 \cdot 3$, CI 0.7 to $2 \cdot 4$ ). In addition, a similar increase in risk was noted for those in the highest quintile of calorie intake compared to those in the lowest (RR 1.4, CI 0.6 to 3.2).

To take account of these trends in confounding variables relative risks were estimated using a logistic regression model in which smoking, social class, and relative weight were entered stepwise (Table IV). These showed that increased vegetable fibre intake above the base quintile was associated with a reduced risk of ulcer, while the lowest quintile of intake was always associated with the lowest risk. For refined sugar intake the pattern of relative risk 
TABLE IV Relative risks (and 95\% confidence intervals) by quintiles of calorie adjusted and unadjusted intake of nutrients controlled for social class, smoking, and relative weight (Quetelet's index)

\begin{tabular}{|c|c|c|c|c|c|}
\hline \multirow[b]{3}{*}{ Nutrient } & \multicolumn{5}{|c|}{ Quintile } \\
\hline & \multicolumn{2}{|c|}{ Lowest } & \multirow[b]{2}{*}{3} & \multicolumn{2}{|l|}{ Highest } \\
\hline & 1 & 2 & & 4 & 5 \\
\hline \multicolumn{6}{|l|}{ Total fibre: } \\
\hline Unadjusted & $1 \cdot 0$ & 0.80 & $1 \cdot 3$ & 0.87 & 1.9 \\
\hline Calorie adjusted & $1 \cdot 0$ & $\begin{array}{l}1.0 \\
(0.35 \text { to } 2.9)\end{array}$ & $\begin{array}{l}1 \cdot 1 \\
(0 \cdot 36 \text { to } 3 \cdot 5)\end{array}$ & $\begin{array}{l}1.6 \\
(0.51 \text { to } 4.8)\end{array}$ & $\begin{array}{l}1.7 \\
(0.54 \text { to } 5 \cdot 7)\end{array}$ \\
\hline \multicolumn{6}{|l|}{ Cereal fibre: } \\
\hline Unadjusted & $1 \cdot 0$ & $0 \cdot 40$ & 0.68 & 0.45 & $1 \cdot 2$ \\
\hline Calorie adjusted & $1 \cdot 0$ & $\begin{array}{l}2 \cdot 0 \\
(0.65 \text { to } 6.0)\end{array}$ & $\begin{array}{l}1 \cdot 5 \\
(0.53 \text { to } 4.4)\end{array}$ & $\begin{array}{l}1 \cdot 0 \\
(0 \cdot 35 \text { to } 3 \cdot 1)\end{array}$ & $\begin{array}{l}3.0 \\
(0.78 \text { to } 11 \cdot 3)\end{array}$ \\
\hline \multicolumn{6}{|l|}{ Vegetable fibre: } \\
\hline Unadjusted & $1 \cdot 0$ & 0.51 & 0.44 & 0.92 & $0 \cdot 71$ \\
\hline Calorie adjusted & $1 \cdot 0$ & $\begin{array}{l}0.49 \\
(0.45 \text { to } 1.5)\end{array}$ & $\begin{array}{l}0.61 \\
(0.23 \text { to } 1.6)\end{array}$ & $\begin{array}{l}0.95 \\
(0.39 \text { to } 3 \cdot 2)\end{array}$ & $\begin{array}{l}0.93 \\
(0.31 \text { to } 2.8)\end{array}$ \\
\hline \multicolumn{6}{|l|}{ Refined sugar: } \\
\hline Unadjusted & $1 \cdot 0$ & $5 \cdot 1$ & $3 \cdot 5$ & $3 \cdot 5$ & $2 \cdot 7$ \\
\hline Calorie adjusted & $1 \cdot 0$ & $\begin{array}{l}5 \cdot 7 \\
(1.6 \text { to } 20.5)\end{array}$ & $\begin{array}{l}4 \cdot 0 \\
(1 \cdot 0 \text { to } 16 \cdot 4)\end{array}$ & $\begin{array}{l}4 \cdot 5 \\
(1 \cdot 1 \text { to } 18 \cdot 7)\end{array}$ & $\begin{array}{l}3 \cdot 8 \\
(0.95 \text { to } 15 \cdot 6)\end{array}$ \\
\hline
\end{tabular}

These confidence intervals refer to the calorie adjusted relative risk.

was consistent with a threshold effect rather than a dose-response relation and the lower confidence intervals were greater or equal to 1 for three of the four quintiles. For vegetable fibre intake, calorie adjustment tended to reduce the evidence for a protective effect and the confidence intervals were wide enough to include a disease promoting effect. Consistent trends were not obtained for total fibre or cereal fibre intake before adjusting for calorie intake. After adjustment for calorie intake the data suggested that increased intake of both tended to be associated with raised risks, but there was no evidence of any dose-response relation and the confidence intervals were wide enough to include a protective effect.

To allow for possible confounding of intake of one nutrient by another, a final set of analyses was performed in which calorie adjusted intakes of fibre and refined sugar were examined while

TABLE V Relative risks (and 95\% confidence intervals) by quintiles of calorie adjusted intake of fibre and refined sugar controlled for covariates (social class, smoking, Quetelet's index) and intake of refined sugar

\begin{tabular}{|c|c|c|c|c|c|}
\hline \multirow[b]{3}{*}{ Nutrient } & \multicolumn{5}{|c|}{ Quintile } \\
\hline & \multicolumn{2}{|c|}{ Lowest } & \multirow[b]{2}{*}{3} & \multicolumn{2}{|l|}{ Highest } \\
\hline & 1 & 2 & & 4 & 5 \\
\hline Total fibre ${ }^{\star}$ & $1 \cdot 0$ & \multirow{5}{*}{$\begin{array}{l}0.56 \\
(0.17 \text { to } 1.9) \\
0.57 \\
(0 \cdot 17 \text { to } 1 \cdot 9) \\
0.37 \\
(0 \cdot 13 \text { to } 1 \cdot 1) \\
3 \cdot 8 \\
(1 \cdot 1 \text { to } 13) \\
4 \cdot 5 \\
(1 \cdot 2 \text { to } 17)\end{array}$} & \multirow{5}{*}{$\begin{array}{l}0.68 \\
(0.21 \text { to } 2 \cdot 2) \\
0.67 \\
(0.22 \text { to } 2 \cdot 1) \\
0.45 \\
(0.15 \text { to } 1 \cdot 4) \\
2 \cdot 5 \\
(0.6 \text { to } 11) \\
2 \cdot 8 \\
(0.7 \text { to } 11)\end{array}$} & \multirow{5}{*}{$\begin{array}{l}0 \cdot 89 \\
(0 \cdot 28 \text { to } 2 \cdot 9) \\
0 \cdot 61 \\
(0 \cdot 20 \text { to } 1 \cdot 9) \\
0 \cdot 65 \\
(0 \cdot 19 \text { to } 2 \cdot 2) \\
2 \cdot 8 \\
(0 \cdot 7 \text { to } 12) \\
3 \cdot 1 \\
(0 \cdot 7 \text { to } 13)\end{array}$} & \multirow{5}{*}{$\begin{array}{l}1 \cdot 12 \\
(0.34 \text { to } 3 \cdot 7) \\
1 \cdot 3 \\
(0.48 \text { to } 3 \cdot 8) \\
0 \cdot 56 \\
(0 \cdot 19 \text { to } 1 \cdot 7) \\
3 \cdot 0 \\
(0 \cdot 7 \text { to } 13) \\
3.9 \\
(0.9 \text { to } 17)\end{array}$} \\
\hline Cereal fibre ${ }^{\star}$ & $1 \cdot 0$ & & & & \\
\hline Vegetable fibre ${ }^{\star}$ & $1 \cdot 0$ & & & & \\
\hline Refined sugart & $1 \cdot 0$ & & & & \\
\hline Refined sugar $\ddagger$ & $1 \cdot 0$ & & & & \\
\hline
\end{tabular}

^Adjusted for refined sugar intake; tadjusted for total fibre intake;

ładjusted for vegetable fibre intake.

TABLE VI Comparison of the dietary intake of control subjects with data from the National Food Survey $1981^{1+}$

\begin{tabular}{|c|c|c|c|c|c|}
\hline \multirow{2}{*}{$\begin{array}{l}\text { Mean intake } \\
\text { of nutrient }\end{array}$} & \multirow{2}{*}{$\begin{array}{l}\text { National Food } \\
\text { Survey } 1981\end{array}$} & \multicolumn{2}{|c|}{ Cade et al $1988^{13}$} & \multicolumn{2}{|c|}{$\begin{array}{l}\text { Control subjects' intake } \\
\text { (this study) }\end{array}$} \\
\hline & & Women & Men & Women & Men \\
\hline $\begin{array}{l}\text { Carbohydrate }(\mathbf{g}) \\
\text { Fat }(\mathbf{g}) \\
\text { Protein }(\mathbf{g}) \\
\text { Fibre }(\mathbf{g})\end{array}$ & $\begin{array}{r}264 \\
104 \\
72 \\
19\end{array}$ & $\begin{array}{c}190-205 \\
72-73 \\
63-66 \\
14-16\end{array}$ & $\begin{array}{c}270-315 \\
97-108 \\
84-95 \\
18-21\end{array}$ & $\begin{array}{r}198 \\
79 \\
71 \\
15\end{array}$ & $\begin{array}{r}233 \\
121 \\
82 \\
21\end{array}$ \\
\hline
\end{tabular}

the intake of one or other nutrient as well as the previously identified covariates (social class, smoking, relative weight) were controlled for. Table V shows that controlling for differences in refined sugar intake had little effect on the inconsistent relations for total or cereal fibre intakes. The inverse relation between vegetable fibre intake and ulcer evident in Table IV was marginally strengthened by controlling for refined sugar intake, but at all intake levels the confidence intervals included one. The relation between refined sugar intake and ulcer was slightly weakened but remained stronger than any of the relations with fibre intake.

Inquiries about past dietary changes in patients and control subjects showed that 46 $(52 \%)$ of the patients and only $10(6 \%)$ of the controls claimed to have changed their diets because of indigestion; 16 of the 42 ulcer patients had reduced their intake of spices, 11 of fried foods, eight of coffee and soft drinks, three of citrus fruit, and two of sugar intake, and six had increased the frequency of meals. In the eight patients who had reduced coffee intake five habitually added sugar. All 10 control subjects reported reducing fried food intake. There were no claims by patients or control subjects of having increased or reduced fibre intake.

\section{Discussion}

Our data provide no support for the proposition that a high total fibre or cereal fibre intake protects from duodenal ulceration. The data do support an association between duodenal ulceration and refined sugar intake and, to a less extent, vegetable fibre intake. Before accepting these findings we have to examine the validity of the data in terms of the suitability of the patient and control series and the validity of the dietary measurements.

The patient series was recruited from all patients within a defined geographic area who were found to have a duodenal ulcer at endoscopy over a 12 month period. How representative this series was of all patients with duodenal ulcer in Nottingham is a matter of conjecture. Half did present with recurrent disease and it is likely that referral for endoscopy was influenced by disease severity. Clearly this is a selected group. Nevertheless, there is no overwhelming reason for believing that as far as their diets are concerned they are unrepresentative of duodenal ulcer patients in general.

The age-sex matched control series was identified from the patient lists of general practitioners from the same area of Nottingham as the matched patients. This method has proved satisfactory in many studies and our control response rate of $85 \%$ was identical to that obtained by Cade and others in their study of English diets. ${ }^{13}$ Furthermore, the estimated nutrient intake of our control subjects (Table VI) was similar to their estimates obtained with an interviewer and a 24 hour diary. Our estimates are also consistent with those published in the 1981 National Food Survey. ${ }^{1+}$

We cannot be sure that the dietary habits of the patients also applied before duodenal ulcer appeared or applied when predisposing factors to 
ulcer operated. Nevertheless, recent studies of diet have indicated that current habits reflect those of the past. ${ }^{\text {is }}$ Although many patients and some control subjects reported some dietary changes as a result of dyspepsia, in most this amounted to a reduction in the intake of spicy and fried foods. Despite the current healthy diet lobby there were no claims of increased (or decreased) fibre intake by patients or control subjects. Furthermore, the claimed reductions in refined sugar intake by patients will have reduced case-control differences and thus had a conservative effect.

The confounding effects of smoking, social class, obesity, and energy intake were allowed for by using logistic regression analysis. As shown in Table IV, the result of this analysis was to eliminate any association between duodenal ulceration and low total fibre or cereal intake, and to strengthen the relation with refined sugar intake, while the weak relation with vegetable fibre intake was scarcely affected. The lack of gradient of ulcer risk with increasing sugar intake may reflect changes in diet by ulcer patients previously alluded to or might indicate a threshold effect for the relevant pathogenic mechanism. The mechanism whereby a low refined sugar intake in itself might protect against duodenal ulceration is not known. Cleave's original suggestion was that a high refined carbohydrate intake accompanied a low intake of unrefined carbohydrate and other sources of dietary fibre and that it was the lack of protein buffer to gastric acid in refined carbohydrate foods that promoted duodenal ulceration. ${ }^{+5}$ As Table V shows, our data provide little support for this as the relation with refined sugar intake was scarcely affected by controlling for fibre intake. It is notable that a high refined sugar intake has been consistently found to be associated with Crohn's disease. ${ }^{16} 17$ The pathogenic mechanism remains unclear, but, as Heaton has pointed out, sucrose is the only osmotically active molecule ingested in large quantities and sugar rich meals can render the gastric contents hypertonic. ${ }^{17}$ Ingestion of hypertonic solutions has been shown by Menzies and colleagues to result in increases in small intestinal permeability, a phenomenon that may be a marker of predisposition to Crohn's disease. ${ }^{18-20}$ Whether changes in intestinal permeability might also predispose to duodenal ulceration is not known.

Although our results provide some evidence for the role of refined sugar intake in the aetiology of duodenal ulcer, larger studies are needed to confirm and clarify this relation.

BK was supported by Deutsche Forschungsgemeinschaft, grant number Ka 665/1-1.

1 Anonymous. Diet and peptic ulcer [Editorial]. Lancet 1987; ii: 80-1.

2 Malhotra SL. Peptic ulcer in India and its aetiology. Gut 1964; 5: 412-6.

3 Tovey FI, Tunstall M. Duodenal ulcer in black populations in Africa south of the Sahara. Gut 1975; 16: 564-76.

4 Cleave TL. Peptic ulcer. Bristol: Wright, 1962.

5 Cleave TL. The saccharine disease. Bristol: Wright, 1974

6 Malhotra SL. A comparison of unrefined what and rice diets in the management of duodenal ulcer. Postgrad Med $\mathcal{F} 1978 ; 54$ : 6-9.

7 Rydning A, Berstad A, Aadland E, Odegaard B. Prophylactic effect of dietary fibre in duodenal ulcer disease. Lancet 1982; ii: 736-8.

8 Paul AA, Southgate DAT. McCance and Widdowson's the composition of foods. 4th ed. London: HMSO, 1978.

9 Paul AA, Southgate DAT, Russel J. First supplement to McCance and Widdowson's the composition of foods. London: MMCance and

10 Wiles SJ, Nettleton PA, Black AE, Paul AA. The nutrient composition of some cooked dishes eaten in Britain: a supplementary food composition table. F Hum Nutr 1980; 34: 189-223.

11 Breslow NE, Day NE. Statistical methods in cancer research. Vol I. The analysis of case-control studies. Lyon: International Agency for Research on Cancer, 1980.

12 Office of Population Censuses and Surveys. Classification of occupations. London: HMSO, 1980.

13 Cade JE, Barker DJP, Margetts BM, Morris JA. Diet and inequalities in health in three English towns. Br Med f 1988; 296: 1359-62.

14 Ministry of Agriculture, Fisheries and Food. Household food consumption and expenditure 1981. London: HMSO, 1983.

15 Rohan TE, Potter JD Retrospective assessment of dietary intake. Am f E pidemiol 1984; 120: 876-87.

16 Persson PG, Ahlbom A, Hellers G. Crohn's disease and ulcerative colitis - a review of dietary studies with emphasis on methodologic aspects. Scand $\mathcal{F}$ Gastroenterol 1987; 22: 385-9.

17 Heaton KW. Dietary sugar and Crohn's disease. Canadian $\mathcal{f}$ Gastroenterol 1988; 2: 140-3.

18 Laker MF, Menzies IS. Increase in human intestinal permeability following ingestion of hypertonic solutions. $\mathcal{F}$ Physiol 1977; 265: 881-94.

19 Wheeler PG, Menzies IS, Creamer B. Effect of hyperosmolar stimuli and coeliac disease on the permeability of the human gastrointestinal tract. Clin Sci Mol Med 1978; 54: human 501 .

20 Hollander D, Vadheim CM, Brettholz E, Petersen GM, Delahunty $T$, Rotter JI. Increased intestinal permeability in patients with Crohn's disease and their relatives. A possible patients with Crohn's disease and their relatives.
etiologic factor. Ann Intern Med 1986; 105: 883-5. 